\title{
Study on WSR-based community healthy food distribution design method
}

\author{
Walid Kamal ABDELBASSET ${ }^{1,2, *}$ (D) , Gopal NAMBI ${ }^{1}$, Mohamed Abdel-Monem EL-SAKHAWY ${ }^{3,4}$, \\ Mustafa Zuhair MAHMOUD ${ }^{5}$, Basil Saud ALRAWAILI ${ }^{6}$, Shereen Hamed ELSAYED ${ }^{7,8}$
}

\begin{abstract}
While new types of consumer services emerge to fulfill people's diverse requirements, one of the most pressing societal concerns is how to improve the health of the elderly and allow them to live their golden years in good physical and mental health. This research is based on the Whole Systems Research (WSR) method, which expands and improves the theoretical research field of delivery service. The planning and service process of healthy diet opens up new service content and service system for the logistics and delivery industry; the research results of this paper are based on the innovation of systematic service model in three levels: physical, physical, and human, which can broaden the service model for related logistics enterprises and new retail market. The research results of this paper, which are based on the innovation of systematic service model from physical and human levels, can broaden the marketing mode and funding source for related logistics enterprises and new retail market; the overall research process and the application of research method can provide theoretical reference for related research institutions.
\end{abstract}

Keywords: consumer services; societal concerns; senior service market; whole systems research (WSR).

Practical Application: This research is based on the WSR method, which expands and improves the theoretical research field of delivery service. The overall research process and the application of the research method can provide theoretical references for related research institutions.

\section{Introduction}

With the accelerated aging of the Chinese population, how to improve the quality of life of the elderly has attracted the attention of the entire society, especially with the gradual improvement of the material living standard in China, the life expectancy of the elderly population is gradually increasing, how to improve the health condition of the elderly, so that the elderly can spend their old a happy life has attracted the attention of the whole society, especially with the gradual improvement of the material living standard in China, the life expectancy of the elderly population is gradually increasing (An et al., 2021; Ni et al., 2019; Ping et al., 2020; Song \& Yu, 2019). Various physical disorders arise as the functions of the aged's organs deteriorate, causing physical discomfort and psychological stress in the elderly; however, the majority of these diseases may be controlled and treated by food (Zhang et al., 2021). Based on this, this project provides the concept of a healthy food delivery service for the elderly, with the goal of improving the elderly's dietary health through the service's design while also encouraging the elderly's diet consumption to be upgraded. The primary motivation for establishing a healthy diet delivery service for the elderly is that they are easily ignored in new services and are undervalued by businesses and the market (Angulo et al., 2020).

Food consumption services that are closely related to life have been upgraded in recent years; however, due to the wide age range of the user group of food consumption services, enterprises frequently overlook the needs of elderly users when planning services and this isolation of needs directly leads to the marginalization of the elderly. The needs of the elderly are growing as people live longer, but as previously stated, a large number of emerging services still cater to young users, which is not friendly to the elderly; furthermore, despite the fact that the proportion of elderly Internet users is growing, many people still have a pessimistic attitude toward the elderly, believing that they are out of touch (Cheng et al., 2019; Yu et al., 2019; Zhang et al., 2019; Molajou et al., 2021). As a result, the author is upbeat and enthusiastic about the senior service market and intends to develop a new healthy diet delivery service design strategy for the elderly through the research of healthy diet delivery service design for the elderly. A preliminary definition 
of the research's scope is as follows: the design of a healthy diet delivery service for the elderly is based on a new retail service model, and the research is aimed at determining how to promote the elderly's health freedom, assist the elderly in upgrading their diet consumption, and meet the demand for a healthy diet through design.

\section{Research background}

\subsection{The progression of aging}

According to the United Nations, China is currently one of the countries with the fastest-growing elderly population (Le Deu et al., 2012; Peng, 2011). By 2022, China's population of adults over 60 years old would reach 255 million, including 118 million senior people living alone and empty nesters. The issue of aging is a serious worry that has an impact on the country's overall position, and the trend of population aging will intensify the problem (Kristof, 1992). The importance of aging in the scientific sciences and the humanities and social sciences reflects its complexity. Geriatric diseases and treatments, aging and anti-aging, nutrition and fitness, nursing care, psychological issues, spiritual comfort, resource development and utilization, cultural activities and learning, family and intergenerational relationships, and so on and so forth are all examples of agingrelated issues (Giri et al., 2016). These issues are not exclusive to China and a few other countries; they affect all aging countries. For the aged, the most immediate and helpful answer is correct knowledge and settlement of these concerns.

This study focuses on the older population and employs this target demographic as the research target is the increasing prominence and importance of aging difficulties in the aging trend (Alvarez \& Sandri, 2018; Tripathi et al., 2014). Aging difficulties present themselves differently in different household contexts as a result of the aging trend. Furthermore, owing to the traditional Chinese culture of filial piety and the notion of aging, aging at home and care by family is still the most frequent mode of aging in China, and institutionalized aging is generally the last alternative for the elderly (Van Hoof et al., 2018; Zhang et al., 2017). When compared to institutionalized aging, aging in place with family care means that the elderly do not live in a standard arrangement and must come up with their own answers to challenges and obstacles. As a result, the elderly in-home care requires services that can help them solve their problems on their own, which is one of the reasons why this paper intends to give new services and empower the elderly in-home care.

\subsection{Food consumption trends}

Consumption has evolved from physical to service consumption, shifting from basic survival to development and enjoyment. According to statistics (Figure 1), the share of household consumption in China is increasing in other service consumption expenditure while decreasing in food consumption support, from around $43 \%$ in 2000 to $28 \%$ in 2010 , and it is predicted to be lowered to 20\% by 2022 (Ding et al., 2017; Lau \& Tang, 2018; Shi, 2021). The data demonstrate that as people become richer, the amount of food consumed decreases, indicating that our people's material living standards have substantially improved, and as a result, people have a greater ability to meet their material and cultural needs. This purchasing pattern demonstrates that individuals are becoming increasingly interested in the total body and spirit experience that expanding basic consumption services may provide, rather than just the current material purchase. In a nutshell, it represents the value individuals place on extra services in their consumption activities.

Food consumption expenditure is the category that has increased the most as people's income has increased (from

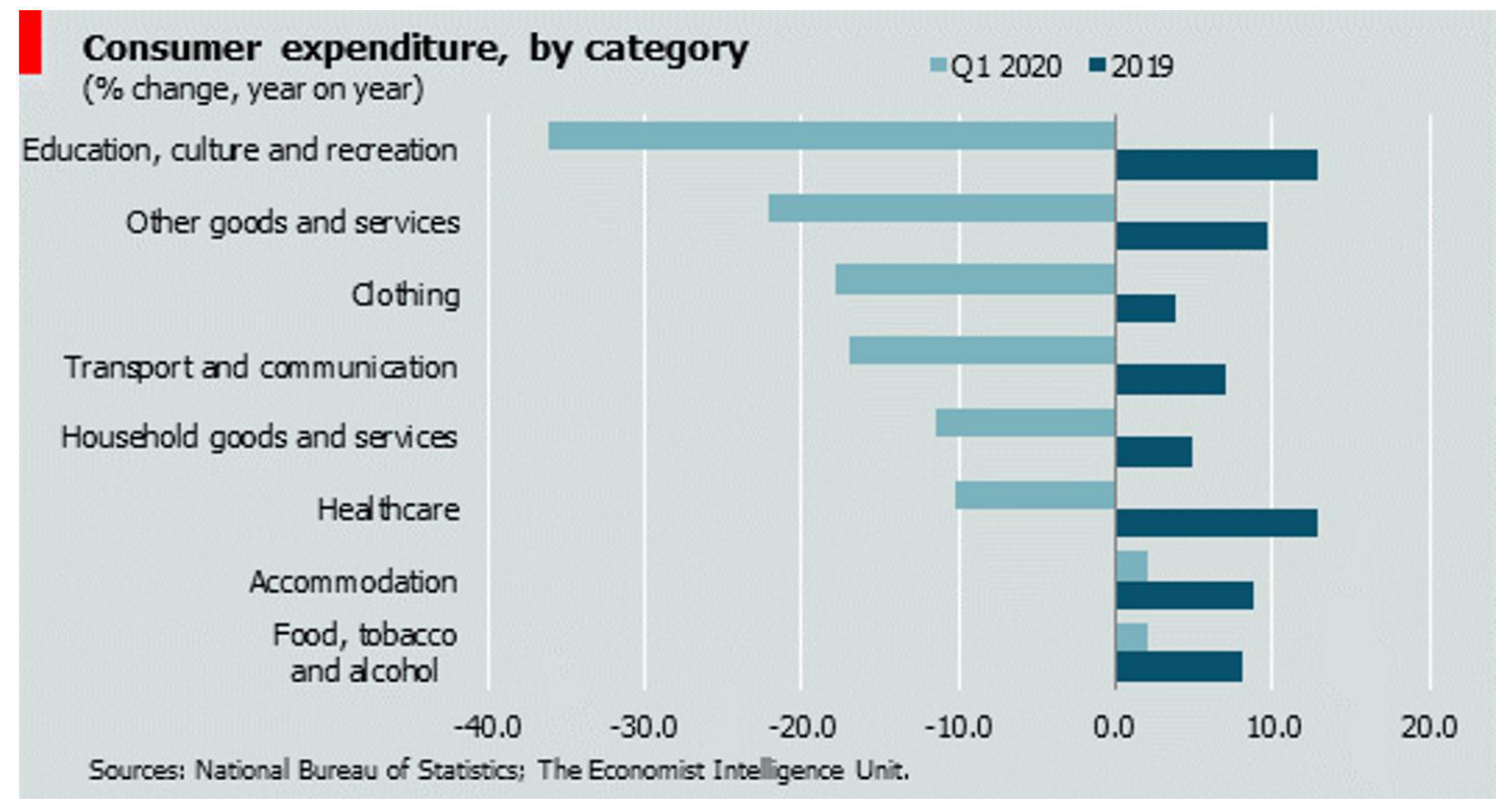

Figure 1. With a few exceptions, consumption fell in the first quarter. 
negative $30 \%$ in 2012 to positive $46 \%$ in 2015 , the proportion of food expenditure has increased by $76 \%$ ); at the same time, it can be found that as people's material living standards have improved, although the proportion of people's food consumption expenditure has increased ( $\mathrm{Li}$ et al., 2021; Li et al., 2019). The aged population also has a requirement for higher levels of food consumption. When perusing material, the elderly pay a lot of attention to health and recipes and other diet-related topics. This demonstrates that the elderly's food demand is not confined to the basic physiological requirement to eat enough but also includes information on how to eat more healthily and how to eat to help with health and old age diseases (Yu, 2018).

\section{A review of related theories and concepts}

\subsection{Formation of WSR systematics methodology}

From the late 1970s to the mid-1980s, systems engineering methodology, as represented by Hull, was the main systems analysis approach in our country as well as in the West. In the United States, due to the successful application of systems engineering and systems analysis methods in aerospace and other industries, people then sought to apply them to solve social and economic problems (Wang \& Li, 2019; Zhao et al., 2020b).

However, the reality later showed that excessive quantification and mathematical modeling could not solve some practical social problems. In August 1980, the International Institute for Applied Systems Analysis (IIASA) organized a seminar on the theme of "Rethinking the Process of Systems Analysis," in which the participants believed that the main reason why quantitative methods could not be applied well in socio-economic and environmental problems was that the methodology was not correct and the problems were too dependent on the establishment of mathematical models
(Checkland, 1984; Tomlinson \& Kiss, 2013; Pouladi et al., 2020). The results of the seminar, "Rethinking the Process of Operations Research and Systems Analysis," were published in 1984 (Tomlinson, 1984). It summarized the origins and development of modern systems thinking, arguing that hard systems methodology emerged from natural science and engineering technology, and soft systems engineering methodology emerged from economic and social issues and expressed these understandings centrally in what he called a "system motion diagram These understandings are expressed in what he calls "system motion diagrams", ending with soft system methodology.

WSR is the abbreviation of "Physical (Wuli) - Reason (Shili) - Human Reason (Renli)," which was proposed in 1994 at HULL University, UK, by the famous Chinese system science experts, Prof. Gu Jifa and Dr. Zhu Zhichang (Figure 2) (Gu \& Zhu, 2000).

It is both a methodology and a tool for solving complex problems. In observing and analyzing problems, especially in observing and analyzing systems with complex characteristics, WSR embodies its uniqueness and has the traditional Chinese philosophical thinking, and is a synthesis and unification of various methods; according to the specific situation, WSR organizes and hierarchizes the group of methods, and plays the effect of simplifying the complexity (Wang \& Li, 2019; Zhao et al., 2020a, b). Foreign scholars classify WSR as one of the integrated system methodologies together with TOP (Technical perspective, Organizational perspective, Personal perspective) and TSI (Total Systems Intervention) (Flood, 1996; Jackson, 2020; Lin et al., 2009). According to WSR methodology, although some existing system theories and methods are feasible for analyzing problems that seem to have a clear physical structure or even a clear matter structure on the surface, they are not as effective in practice, mainly because they ignore or do not have a clear human structure and get half the results.

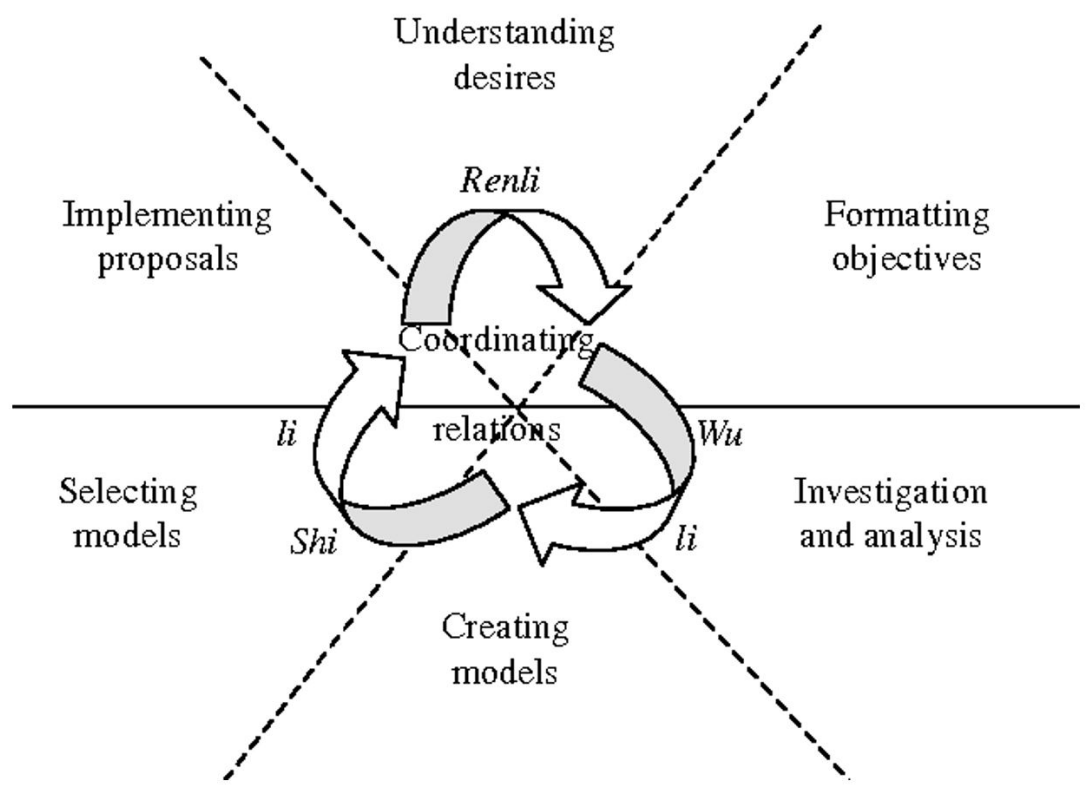

Figure 2. The Wuli-Shili-Renli approach. 
In the WSR system methodology, "physics" refers to the mechanisms involved in the movement of matter, which includes physics in a narrow sense and chemistry, biology, geography, astronomy, and so on (Zhao et al., 2020b). Usually, natural science knowledge is used to answer mainly what "things" are, such as the law of gravity describing free fall, the genetic code carried by the double helix in DNA, and the principle of nuclear power plants, which converts the huge energy generated by nuclear reactions into electricity. Physics requires realism, the study of objective reality. The knowledge imparted by university science and engineering faculties is used to solve various "physical" problems. The "theory of things" refers to the rationale for doing things, mainly addressing how to arrange all the equipment, materials, and people. Knowledge of operations research and management science is often used to answer the question "how to do it." Typical examples are the Apollo program, the construction of nuclear power plants, and the design and management of supply chains (Ji et al., 2018; Zhu, 2000).

Systems engineering and industrial engineering in engineering schools, management science in management schools, and operations research and control theory in engineering and science schools all teach the basics of answering "how-to" questions, and there is already some specialized research in operations research. For the future development of operations research, one view is to move from operations research to the science of things. "Human science" refers to the reasoning of being a human being, which usually requires the knowledge of humanities and social sciences to answer the questions of "what should be done" and "how best to do it."

The role of human reasoning can be reflected in worldview, culture, belief, religion, and emotion, especially in the interests and values of people in dealing with some "things." In dealing with the world, it can be expressed in how to better understand things and learn knowledge, how to stimulate human creativity, arouse human enthusiasm, and develop human wisdom (Zhu et al.,
2008). The "human reasoning" is also expressed in its influence on physical and material reasoning. For example, although nuclear power may be more economical for Japan, where resources and land are scarce, there are places where people are afraid of the possibility of nuclear accidents and radiation, and they oppose, protest, or even veto the construction of nuclear power plants.

The humanities and management faculties of universities offer courses on the basics of analyzing humanistic issues. Systemic practice is the dynamic unity of the material world, system organization, and human beings. Our practical activity should cover these three aspects and their interrelationships, i.e., consider "physical," "material," and "human" aspects, and thus obtain a satisfactory and comprehensive understanding and conception of the object under investigation. In order to obtain a satisfactory and comprehensive understanding of the object under investigation (Scenario), or a deeper understanding of the object under investigation, in order to take an appropriate and feasible response.

Classroom education only transmits the basic knowledge, while the understanding and practice form the "new knowledge" or "knowing." Knowing is a person who can organize and encourage people to make good use of the knowledge they have for people's benefit, develop in-depth and concrete practices, and actively learn new things (Su \& Tian, 2011).

Figure 3 briefly lists the main elements of physical, practical, and human knowledge. "Physics, reasoning, and human reasoning are the three aspects of systematic practice that need to be examined together (Liu \& Li, 2019; Wan \& Xiaoyong, 2017).

If we only pay attention to "physics" and "reasoning" and ignore "human reasoning," we will inevitably do things mechanically, lack adaptability and communication, no emotion and passion, and it is difficult to have strategic innovation, which is likely to achieve the overall goal of the system. It is likely to fail to achieve the overall goal of the system, or even go in the

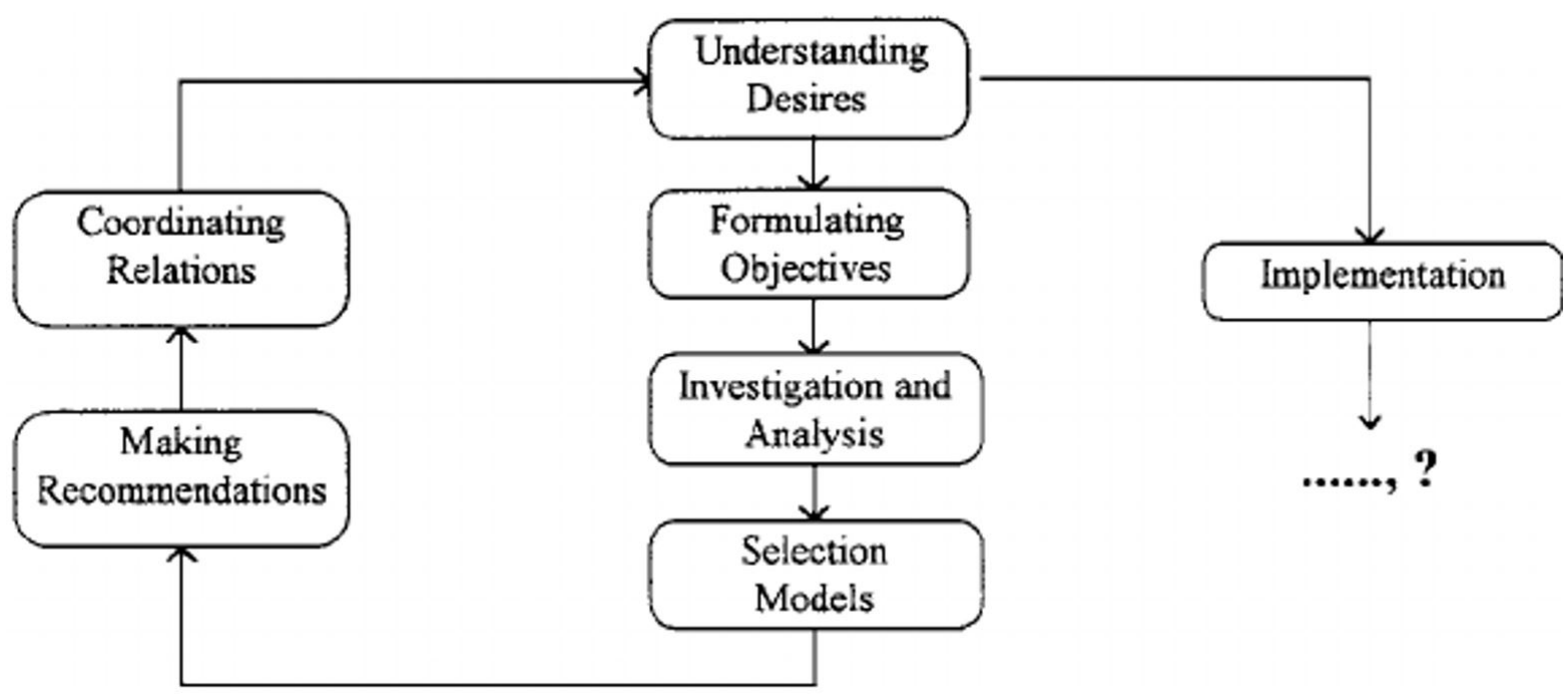

Figure 3. The working process of the WSR approach. 
wrong direction or fail to propose new goals; if the emphasis is placed on "human reasoning" while going against "physical" and "material reasoning," it will also lead to failure, such as Some dedication projects, chief projects, etc. do not do a full investigation and research in advance, only by the leadership of a few experts subjective wishes and lead to the failure of some projects fully illustrates this point. "Understanding physics, understanding things, and understanding people" is the practice guideline of WSR system methodology. To put it simply, to describe a person's understanding is to summarize his or her successful practice of WSR.

\subsection{Key principles of WSR system methodology}

In applying the WSR methodology, we often focus on following the following principles (Ji et al., 2018; Li et al., 2020; Wu et al., 2020; Yan \& Lv, 2019):

\section{Principle of synthesis}

To synthesize all kinds of knowledge, it is necessary to listen to all kinds of opinions, take their strengths, and compensate each other in order to help obtain a reachable conception (scenario) about the practice object, which first expects the active participation of all relevant people.

\section{Participation principle}

Through participation, full participation, or good communication between different people (or groups) helps to understand each other's intentions, design reasonable goals, choose feasible strategies, and correct unrealistic ideas. In practice, often some users think that after the money is the project team does not actively participate, or some project team has a general understanding of the situation after the user does not contact and go behind closed doors, so nine out of ten projects will fail, so the establishment of the project team and the overall coordination team need to be the corresponding user party to participate.

\section{Operational principles}

The selected method should be closely integrated with practice, and the results of practice need to be used by users. Consider the operability, not only the superficial operability, such as a friendly human-machine interface, etc., but also the operability of the whole practice, such as the operability of the goals, strategies, and programs, the influence of culture and worldview on the operability of these goals and strategies, and whether the final results are understood and used by the users and how much they are available. In addition, users must be taught to operate themselves, often sometimes because the development side will operate and the user only see them operate, so that the project is closed and through the identification, the development side of a withdrawal of people, some operations cannot be carried out.

\section{Iteration principle}

People's cognitive process is interactive, cyclical, and learning process, from the goal to the strategy to the program to the implementation of the result reflects the practitioner's awareness and decision-making, subjective evaluation, compromise on conflicts, etc. Therefore, the process of using WSR is iterative. The focus on the physical, physical, and human aspects will be different at each stage, and it is not required to handle all three at the same time. It is inevitable that some costs will be incurred in the system practice for extremely complex and inexperienced situations, and it is not possible to gain insight into everything, but practitioners should try to be as thorough as possible beforehand.

\section{Designing physical layer strategies for elderly healthy diet delivery services}

\subsection{Differentiation strategy}

By transporting the needs of elderly users, find out the market differentiation opportunities and clarify the service advantages. First, find the target senior citizens. As known, in terms of the financial independence and education level of elderly users, "urban elderly" is more willing to accept the service than rural elderly; in terms of the population density and consumption-ability of elderly users, "first- and second-tier cities" are more likely to take the lead than third- and fourth-tier cities (Waxman, 2021; Zhiming et al., 2021). In terms of elderly users' family structure, elderly people who are taken care of by their families (or those who take care of their children) are more passive and influenced by their families, while elderly people who live alone (who prepare their own food) are freer to choose their own food as long as they pay attention to themselves; in terms of immediate needs, ordinary elderly people's demand for food is mainly for daily health and wellness, while special elderly people's demand for foodservice is stronger, including elderly people who are sick (including those who have a medical condition).

In terms of immediate needs, the dietary needs of the general elderly are mainly for daily health and wellness, while the special elderly have stronger needs for dietary services, including the elderly who are sick (with dietary adjustment needs), the elderly who have difficulty with their legs (with delivery needs), and the young elderly who have regular jobs (with time-saving needs) (Denissen et al., 2017). Secondly, we identified the dietary health needs of the target elderly. One type of diet is a general daily healthy diet, and the other type is a targeted healthy diet with therapeutic effect. Regardless of the dietary needs, the service subject of healthy diet delivery service is filled with elderly users, and this service becomes a scarce service in the market nowadays, and this kind of special elderly people are willing to accept the service, which has a market value under the trend of aging (Yan \& Lv, 2019).

\subsection{Dynamic strategy}

Healthy diet service needs to be "dynamically adjusted" according to users' needs because, in the long run, people's needs change periodically or in phases (Mourey et al., 2000; Province et al., 1995). For example, in the case of elderly people who are ill, there is a cyclical plan for disease management, so the dietary needs are different at different stages; for example, 
from the perspective of human psychology, a long time of monotonous and repetitive diet will make people feel bored, so the richness of the diet needs to be constantly updated. "So, how can a diet be dynamically adjusted?" The dynamic strategy of diet progression is analyzed from 3 levels of diet standardization, diversification, and customization (Amin \& Seifert, 2021; Peled \& Fisher, 2014; Zhou et al., 2019).

First of all, "standardization" is the process of standardizing the diet and making things more orderly, which is the basic requirement for diet dynamics. Standardization is the basis for customization and refinement of catering services and is reflected in both "quantity" and "matching." The "quantity" is a restriction on the conditions of customization or refinement (excessive customization and refinement are very costly, and the service cannot survive); that is, there needs to be a minimum unit of sale, assuming that the user can customize or choose $50 \mathrm{~g}$ of a certain diet, $\mathrm{N}$ refers to a natural number that is not zero, then $50 \mathrm{~g}$ is a standardized minimum unit of sale. In addition, there are also standardized restrictions on food "matching." In terms of the properties of ingredients, we will consider whether the food matching is reasonable and whether there is any compatibility; in terms of user preference, we will consider whether an ingredient that most users do not like should be combined or sold separately; in terms of user demand, we will consider how the therapeutic effect of food matching is the standardization makes the service more efficient, and the factors considered in the combination are more complicated. Secondly, "diversification" can meet users' needs for fine matching, i.e., the demand for a healthy and balanced diet of "small amount and variety," which is a kind of intermediate dynamics.

The key to providing users with rich choices is the choice of the "ultimate single product," the so-called single product is the smallest product that causes users to buy demand, as the saying goes, "A thousand-foot-high building starts from the ground," the single product is the basis for the realization of the richness of the diet, and is also the material prerequisite for diet It is also a prerequisite for diversification. Convenience store giant 7-11 has more than 4,800 items available at its headquarters and recommends 100 new items to each store every week, with an annual replacement rate of $70 \%$. This shows that the ultimate single product is not achieved overnight. First of all, it is necessary to carry out basic stocking according to users' needs and preferences, and then to rapidly iterate on the single product according to the data of sales dynamics, and in this process, the single product is formed to satisfy users and change dynamically with users' needs.

Finally, "customization" is undoubtedly the best way to meet users' needs in terms of dynamic dietary adjustments, as customization allows users to freely combine food types and portions. In fact, the "just for you" service customization strategy is less practiced in China, and a more representative service provider is UNIQLO. Although customization in UNIQLO is a small part of user demand, it extends user demand's overall satisfaction, brings a unique differentiation advantage to UNIQLO, and forms a high reputation of user service experience.

\section{Conclusions}

This project is based on the current situation of senior health, targeting the new service model of food delivery service, exploring the service experience and user needs of senior health food delivery based on the WSR method, and proposing the corresponding design guidance method. The service design scope is proposed. The service elements and minimum feasible service process and service tools are constructed based on case studies. The elements, process, and tools are tested and verified based on user studies. Service model. The main conclusions of the thesis include the following aspects:

\section{A service model based on WSR theory.}

By dividing the physical level, the physical level, and the human level in WSR theory, the complexity of the research on the design of healthy diet delivery services for the elderly is reduced, and the research is made more comprehensive and systematic, and the service model of healthy diet delivery service for the elderly is proposed from both case studies and user studies.

\section{User model based on the case study and user research.}

Through the case study, the service elements, service process, and service tools are constructed and combined with the qualitative and quantitative analysis in the user study, the service demand of the elderly users is assessed, and the user model is constructed to visually show the typical user types and market opportunities of the elderly healthy diet delivery service.

3. The design principles and design strategies of healthy diet delivery service for the elderly were proposed.

Based on the case study and user research results, we proposed five physical coordination principles: richness, aesthetics, science, systematization, and uniqueness; five physical coordination principles: experience, efficiency, convenience, safety, and accessibility; and three human coordination principles: synergy, age-ability, and independence. Under the guidance of the 13 design principles in the physical and human levels, strategies are constructed for the ideal senior delivery service scenario, and two strategies are proposed, namely, differentiation and dynamization; four strategies are proposed, namely, informationization, scenarioization, precision, and integration; five strategies are proposed in the human level, namely, circle differentiation, service expansion, emotion building, personality building and self-actualization, which include 11 design strategies in the physical and human levels. A total of 11 design strategies at the physical and human levels are proposed.

\section{Acknowledgment}

This research was funded by the Deanship of Scientific Research at Princess Nourah bint Abdulrahman University through the Fast-track Research Funding Program.

\section{References}

Alvarez, Â. M., \& Sandri, J. V. A. (2018). Population aging and the nursing commitment. Revista Brasileira de Enfermagem, 71(suppl 2), 722-723. https://doi.org/10.1590/0034-7167-201871Sup201. 
Amin, N., \& Seifert, J. (2021). Dynamic progression of the calf's microbiome and its influence on host health. Computational and Structural Biotechnology Journal, 19, 989-1001. http://dx.doi. org/10.1016/j.csbj.2021.01.035. PMid:33613865.

An, J., Zhou, H., Yang, T., Duan, C., Bao, C., Wan, C., Shen, Y., \& Wen, F. (2021). Relationship of psychological factors with daily activities and quality of life in patients with chronic obstructive pulmonary disease in a Chinese rural population. Annals of palliative medicine, 10(2), 1675-1684. PMid:33222460.

Angulo, J., El Assar, M., Álvarez-Bustos, A., \& Rodríguez-Mañas, L. (2020). Physical activity and exercise: Strategies to manage frailty. Redox Biology, 35, 101513. http://dx.doi.org/10.1016/j.redox.2020.101513. PMid:32234291.

Checkland, P. (1984). Rethinking a systems approach. In R. Tomlinson \& I. Kiss (Eds.), Rethinking the process of operational research \& systems analysis (pp. 43-60). USA: Elsevier. http://dx.doi.org/10.1016/ B978-0-08-030830-2.50009-X.

Cheng, Y., Rosenberg, M., Winterton, R., Blackberry, I., \& Gao, S. (2019). Mobilities of older Chinese rural-urban migrants: a case study in Beijing. International Journal of Environmental Research and Public Health, 16(3), 488. http://dx.doi.org/10.3390/ijerph16030488. PMid:30744061.

Denissen, K. F. M., Janssen, L. M. J., Eussen, S., Van Dongen, M., Wijckmans, N. E. G., Van Deurse, N. D. M., \& Dagnelie, P. C. (2017). Delivery of nutritious meals to elderly receiving home care: feasibility and effectiveness. The Journal of Nutrition, Health \& Aging, 21(4), 370-380. http://dx.doi.org/10.1007/s12603-0160790-2. PMid:28346563.

Ding, Q., Cai, W., Wang, C., \& Sanwal, M. (2017). The relationships between household consumption activities and energy consumption in china-An input-output analysis from the lifestyle perspective. Applied Energy, 207, 520-532. http://dx.doi.org/10.1016/j. apenergy.2017.06.003.

Flood, R. L. (1996). Total systems intervention. In R. L. Flood \& N. R. A. Romm (Eds.), Critical systems thinking (pp. 95-115). USA: Springer. http://dx.doi.org/10.1007/978-0-585-34651-9_6.

Giri, M., Chen, T., Yu, W., \& Lü, Y. (2016). Prevalence and correlates of cognitive impairment and depression among elderly people in the world's fastest growing city, Chongqing, People's Republic of China. Clinical Interventions in Aging, 11, 1091-1098. http://dx.doi. org/10.2147/CIA.S113668. PMid:27574409.

Gu, J., \& Zhu, Z. (2000). Knowing Wuli, sensing Shili, caring for Renli: methodology of the WSR approach. Systemic Practice and Action Research, 13(1), 11-20. http://dx.doi.org/10.1023/A:1009567421256.

Jackson, M. C. (2020). Critical systems practice 1: Explore-Starting a multimethodological intervention. Systems Research and Behavioral Science, 37(5), 839-858.

Ji, B., Liu, Y., \& Jin, Z. (2018). An evaluation of the design and construction of energy management platform for public buildings based on WSR system approach. Kybernetes, 47(8), 1549-1568. http://dx.doi. org/10.1108/K-07-2017-0265.

Kristof, N. D. (1992). The rise of China. Foreign Affairs, 72(5), 59. http:// dx.doi.org/10.2307/20045814.

Lau, L. J., \& Tang, J. (2018). The impact of US imports from China on US consumer prices and expenditures. SSRN Electronic Journal, 66. http://dx.doi.org/10.2139/ssrn.3175677.

Le Deu, F., Parekh, R., Zhang, F., \& Zhou, G. (2012). Healthcare in China: entering uncharted waters. Australia: McKinsey \& Company.

Li, G., Han, X., Luo, Q., Zhu, W., \& Zhao, J. (2021). A study on the relationship between income change and the water footprint of food consumption in urban China. Sustainability, 13(13), 7076. http:// dx.doi.org/10.3390/su13137076.

Li, G., Zhou, Y., Liu, F., \& Wang, T. (2020). Regional differences of manufacturing green development efficiency considering undesirable outputs in the yangtze river economic belt based on super-SBM and WSR system methodology. Frontiers in Environmental Science, 8, 299.

Li, Y., Wang, L., \& Cheng, S. (2019). Spatiotemporal variability in urban HORECA food consumption and its ecological footprint in China. The Science of the Total Environment, 687, 1232-1244. http://dx.doi. org/10.1016/j.scitotenv.2019.06.148. PMid:31412458.

Lin, X., Zhang, Q., \& Han, X. (2009). Application of Wuli-Shili-Renli system methodology in knowledge management. Kybernetes, 38(3-4), 346-353. http://dx.doi.org/10.1108/03684920910944038.

Liu, Y., \& Li, M. (2019). Design of practical teaching system for the core course of human resources management specialty. In Proceedings of the 2019 International Conference on Contemporary Education and Society Development (ICCESD 2019) (pp. 233-236). Atlantis Press. http://dx.doi.org/10.2991/iccesd-19.2019.58.

Molajou, A., Afshar, A., Khosravi, M., Soleimanian, E., Vahabzadeh, M. \& Variani, H. A. (2021). A new paradigm of water, food, and energy nexus. Environmental Science and Pollution Research International. http://dx.doi.org/10.1007/s11356-021-13034-1. PMid:33634401.

Mourey, F., Grishin, A., d’Athis, P., Pozzo, T., \& Stapley, P. (2000). Standing up from a chair as a dynamic equilibrium task: a comparison between young and elderly subjects. The Journals of Gerontology. Series A, Biological Sciences and Medical Sciences, 55(9), B425-B431. http:// dx.doi.org/10.1093/gerona/55.9.B425. PMid:10995039.

Ni, J., Song, S., \& Zhou, N. (2019). Impact of surgical orthodontic treatment on quality of life in Chinese young adults with class III malocclusion: a longitudinal study. BMC Oral Health, 19(1), 109. http://dx.doi.org/10.1186/s12903-019-0782-9. PMid:31196054.

Peled, M., \& Fisher, E. A. (2014). Dynamic aspects of macrophage polarization during atherosclerosis progression and regression. Frontiers in Immunology, 5, 579. http://dx.doi.org/10.3389/ fimmu.2014.00579. PMid:25429291.

Peng, X. (2011). China's demographic history and future challenges. Science, 333(6042), 581-587. http://dx.doi.org/10.1126/science.1209396. PMid:21798939.

Ping, W., Zheng, J., Niu, X., Guo, C., Zhang, J., Yang, H., \& Shi, Y. (2020). Evaluation of health-related quality of life using EQ-5D in China during the COVID-19 pandemic. PLoS One, 15(6), e0234850. http://dx.doi.org/10.1371/journal.pone.0234850. PMid:32555642.

Pouladi, P., Afshar, A., Molajou, A., \& Afshar, M. H. (2020). Sociohydrological framework for investigating farmers' activities affecting the shrinkage of Urmia Lake; hybrid data mining and agent-based modelling. Hydrological Sciences Journal, 65(8), 1249-1261. http:// dx.doi.org/10.1080/02626667.2020.1749763.

Province, M. A., Hadley, E. C., Hornbrook, M. C., Lipsitz, L. A., Miller, J. P., Mulrow, C. D., Ory, M. G., Sattin, R. W., Tinetti, M. E., \& Wolf, S. L. (1995). The effects of exercise on falls in elderly patients. A preplanned meta-analysis of the FICSIT Trials. Frailty and injuries: cooperative studies of intervention techniques. Journal of the American Medical Association, 273(17), 1341-1347. http://dx.doi.org/10.1001/ jama.1995.03520410035023. PMid:7715058.

Shi, X. (2021). Influence of human capital on consumer expenditure under big data. In Proceedings of the 2020 International Conference on Data Processing Techniques and Applications for Cyber-Physical Systems (pp. 577-582). Singapore: Springer. http://dx.doi.org/10.1007/978981-16-1726-3_71. 
Song, D., \& Yu, D. S. F. (2019). Effects of a moderate-intensity aerobic exercise programme on the cognitive function and quality of life of community-dwelling elderly people with mild cognitive impairment: a randomised controlled trial. International Journal of Nursing Studies, 93, 97-105. http://dx.doi.org/10.1016/j.ijnurstu.2019.02.019. PMid:30901716.

Su, H., \& Tian, S. (2011). An analysis framework for enterprise knowledge integration based on WSR system methodology. In Proceedings of the 2011 International Conference on Computer and Management (CAMAN) (pp. 1-4). USA: Elsevier. http://dx.doi.org/10.1109/ CAMAN.2011.5778866.

Tomlinson R. (1984). Rethinking the process of systems analysis and operational research: from practice to precept-and back again. In R. Tomlinson \& I. Kiss (Eds.), Rethinking the process of operational research \& systems analysis (pp. 205-221). USA: Elsevier.

Tomlinson, R., \& Kiss, I. (2013). Rethinking the process of operational research \& systems analysis. USA: Elsevier.

Tripathi, R., Kumar, K., Bharath, S., Marimuthu, P., \& Varghese, M. (2014). Age, education and gender effects on neuropsychological functions in healthy Indian older adults. Dementia \& Neuropsychologia, 8(2), 148-154. http://dx.doi.org/10.1590/S1980-57642014DN82000010. PMid:29213896.

Van Hoof, J., Kazak, J. K., Perek-Białas, J. M., \& Peek, S. T. M. (2018). The challenges of urban ageing: making cities age-friendly in Europe. International Journal of Environmental Research and Public Health, 15(11), 2473. http://dx.doi.org/10.3390/ijerph15112473. PMid:30714577.

Wan, Y. E., \& Xiaoyong, L. I. U. (2017). Empirical study on factors affecting the system of science and technology innovation talent development under the perspective of WSR. Science and Technology Management Research, 09.

Wang, Q., \& Li, S. (2019). Shale gas industry sustainability assessment based on WSR methodology and fuzzy matter-element extension model: the case study of China. Journal of Cleaner Production, 226, 336-348. http://dx.doi.org/10.1016/j.jclepro.2019.03.346.

Waxman, E. (2021). Ending hunger in America: examining hunger among seniors and multigenerational families. Washington: Committee on Rules.

Wu, X., Zhang, J., Chen, Y., \& Tang, Z. (2020). A system methodology and its application in developing an emergency response plan for natural gas leakage on an offshore platform. Journal of Coastal Research, 111(SI), 89-92. https://doi.org/10.2112/JCR-SI111-015.1.

Yan, T., \& Lv, Y. (2019). The cause of highly frequent commercial bribery during the invitation and submission of bids for engineering projects and the counteraction. The analysis based on WSR methodology. IOP Conference Series. Materials Science and Engineering, 688(5), 055085. http://dx.doi.org/10.1088/1757899X/688/5/055085.
Yu, R., Leung, J., Lum, C. M., Auyeung, T. W., Lee, J. S., Lee, R., \& Woo, J. (2019). A comparison of health expectancies over 10 years: implications for elderly service needs in Hong Kong. International Journal of Public Health, 64(5), 731-742. http://dx.doi.org/10.1007/ s00038-019-01240-1. PMid:31032531.

Yu, X. (2018). Engel curve, farmer welfare and food consumption in 40 years of rural China. China Agricultural Economic Review, 10(1), 65-77. http://dx.doi.org/10.1108/CAER-10-2017-0184.

Zhang, A., Nikoloski, Z., \& Mossialos, E. (2017). Does health insurance reduce out-of-pocket expenditure? Heterogeneity among China's middle-aged and elderly. Social Science \& Medicine, 190, 11-19. http://dx.doi.org/10.1016/j.socscimed.2017.08.005. PMid:28823943.

Zhang, Y. S., Strauss, J. A., Hu, P., Zhao, Y., \& Crimmins, E. M. (2021). Links between mortality and socioeconomic characteristics, disease burden, and biological and physical functioning in the aging chinese population. The Journals of Gerontology: Series B. gbab059. http:// dx.doi.org/10.1093/geronb/gbab059.

Zhang, Y., Yao, E., Zhang, R., \& Xu, H. (2019). Analysis of elderly people's travel behaviours during the morning peak hours in the context of the free bus programme in Beijing, China. Journal of Transport Geography, 76, 191-199. http://dx.doi.org/10.1016/j. jtrangeo.2019.04.002.

Zhao, J., Sun, F., \& Meng, W. (2020a). Fuzzy comprehensive evaluation of subway shield construction risk based on wsr and combined weighting. Proceedings of the IOP Conference Series: Earth and Environmental Science, 525, 012011.

Zhao, M., Ruan, Y., Yan, P., Dou, C., Wang, S., \& Yin, X. (2020b). Research on training problem based on WSR methodology. In Proceedings of the 2020 IEEE Conference on Telecommunications, Optics and Computer Science (TOCS) (pp. 280-283). USA: IEEE. http://dx.doi.org/10.1109/TOCS50858.2020.9339737.

Zhiming, N., Lele, Z., Yu, Z., Yumeng, T., \& Choi, S. (2021). Design and research of mobile assisted medical system intervention in the elderly community: a case study. In Proceedings of the 2021 2nd Asia Service Sciences and Software Engineering Conference (pp. 74-83).

Zhou, W., Xu, H., Zhan, L., Lu, X., \& Zhang, L. (2019). Dynamic development of fecal microbiome during the progression of diabetes mellitus in Zucker diabetic fatty rats. Frontiers in Microbiology, 10, 232. http://dx.doi.org/10.3389/fmicb.2019.00232. PMid:30837966.

Zhu, Z. (2000). WSR: a systems approach for information systems development. Systems Research and Behavioral Science: The Official Journal of the International Federation for Systems Research, 17(2), 183-203. http://dx.doi.org/10.1002/(SICI)1099-1743(200003/04)17:2<183::AIDSRES293>3.0.CO;2-B.

Zhu, Z., Song, W., \& Gu, J. (2008). Meta-synthesis view toward surveying WSR system approach studies. In Proceedings of the 2008 IEEE International Conference on Systems, Man and Cybernetics (pp. 494499). USA: IEEE. http://dx.doi.org/10.1109/ICSMC.2008.4811325. 